\title{
Establishment of Vehicle Scheduling Model and Algorithm Design Based on Jilt Hang Transport Operation
}

\author{
${\text { Lijiao } \text { Liu }^{1, a} \text { and Jihui Ma }}^{1,2, b}$ \\ ${ }^{1}$ School of Traffic and Transportation, Beijing Jiaotong University, Beijing 100044, China \\ ${ }^{2}$ MOE Key Laboratory for Urban Transportation Complex Systems Theory and Technology, Beijing \\ Jiaotong University, Beijing 100044, China \\ a 16120766@bjtu.edu.cn, ${ }^{b}$ jhma@bjtu.edu.cn
}

Keywords: Jilt hang transport; Operation mode; Vehicle scheduling; Model building; Algorithm design

\begin{abstract}
Based on the analysis of the operation mode of jilt hang transport, this paper establishes a vehicle scheduling model. The optimal path of tractor driving is selected by using multi-objective optimization. The Floyd algorithm is combined with the greedy algorithm to study jilt hang transportation vehicle scheduling. Finally, an example is given to demonstrate the feasibility of the vehicle scheduling model, and the optimal driving route and the rejection scheme of the tractor are obtained.
\end{abstract}

\section{Introduction}

Jilt hang transportation refers to the tractor with trailer to the destination, the trailer will be thrown off, put on a new trailer to another destination of the transport [1]. In jilt hang transport path optimization, a large number of scholars have studied different mathematical algorithms. Usually, the problem of jilt hang transportation and transportation management is reduced to VRP (Vehicle Routing Problem) and VSP (Vehicle Scheduling Problem) [2]. Miller invented the heuristic scanning algorithm (Sweep Method), which aims to solve the multi-objective function of vehicle scheduling problem [3]. Willard applies taboo search method to vehicle scheduling problem, and transforms the VRP problem into TSP (traveling salesman problem) to solve the vehicle scheduling problem [4]. Shi-Wei Lin uses the simulated annealing algorithm to solve the problem [5]. Lei Ping analyzed the mode of jilt hang transportation [6]. Dai Hongyan analyzed the development conditions of jilt hang transportation [7]. Wu Yu gives the determination model of the number of transport vehicles and loading and unloading machinery [8]. Jilt hang transportation can improve vehicle transportation efficiency and reduce transportation costs [9]. How to arrange the tractor, and how to set up the proportion of tractor and trailer, which limits the development of jilt hang transportation. It is necessary to study the core issue of the jilt hang transportation - vehicle scheduling problem [10].

\section{Establishment of Jilt Hang Transportation Vehicle Scheduling Model}

Nomenclature. $\mathbf{G}=\{\mathbf{U}, \mathbf{B}\}$ represents the structure variable transportation network. $\mathbf{U}=$ $\{\mathbf{0}, \mathbf{1}, \mathbf{2} \ldots\}$ is the set of nodes in the transport network. $\mathbf{0}$ is the freight station field, $\mathbf{1}, \mathbf{2}, \mathbf{n} \ldots$ represents each task node. $\mathbf{B}$ represents the path set between loading and unloading points. $\mathbf{K}$ is the total amount of goods shipped within the specified time. $\mathbf{S}$ is the number of tractors. $\mathbf{Z}$ is the total amount of goods carried by each tractor. $\mathbf{T}$ is the time to finish the task. $\mathbf{r}_{\mathbf{k}}$ and $\mathbf{s}_{\mathbf{k}}$ are task $\mathbf{k}$ loading and unloading operations. $\mathbf{q}_{\mathbf{i j}}$ is the operating point $\mathbf{i}$ and the operating point $\mathbf{j}$ unit of traffic. $\mathbf{q}_{\mathbf{0}}^{-}$is the loading requirement of the operating point. $\mathbf{q}_{\mathbf{0}}^{+}$is the unloading demand at the operating point. $\mathbf{q}_{\mathbf{0}}^{-}=\mathbf{q}_{\mathbf{0}}^{+}=\mathbf{0}$. $\left[\mathbf{E T}_{\mathbf{k}}, \mathbf{E T}_{\mathbf{k}}\right]$ is the time window of the task $\mathbf{k} \cdot \mathbf{d}_{\mathbf{i j}}$ is the distance between the operating pointi and $\mathbf{j} . \mathbf{i} \neq \mathbf{j}, \mathbf{d}_{\mathbf{i i}}=\mathbf{0}, \mathbf{d}_{\mathbf{i j}}=\mathbf{d}_{\mathbf{j i}} \cdot \mathbf{d}_{\mathbf{0 i}}$ is the distance between the freight station and the loading and unloading point $\mathbf{i}, \mathbf{d}_{\mathbf{0 i}}=\mathbf{d}_{\mathbf{i} \mathbf{0}} \cdot \mathbf{t}_{\mathbf{s}}$ is a tractor to jilt hang homework time. 
$\mathbf{B}_{\mathbf{r k}}$ is the time for the tractor to reach $\mathbf{r}_{\mathbf{k}} \cdot \mathbf{t}_{\mathbf{k r}}$ is the start moment of tractor $\mathrm{c}$ in the $\mathbf{r}_{\mathbf{k}}$ trailer semi-trailer. $\mathbf{t}_{\mathbf{s k}}$ is the tractor car in the $\mathbf{s}_{\mathbf{k}}$ to get rid of the end of the semi-trailer. $\mathbf{t}_{\mathbf{k}}$ is the total time required to complete the task $\mathbf{k} . \mathbf{t}_{\mathbf{m}, \mathbf{n}, \mathbf{r}}$ is the tractor $\mathrm{c}$ at the begin of the $\mathrm{nth}$ transport mission. $\mathbf{t}_{\mathbf{m}, \mathbf{n}, \mathbf{e}}$ is the tractor $\mathrm{c}$ at the end of the $\mathrm{nth}$ transport mission. $\mathbf{v}_{\mathbf{1}}$ is the average speed of the tractor when it is unload. $\mathbf{v}_{\mathbf{2}}$ is the average speed of the tractor when it is trailing a semi-trailer. $\boldsymbol{\beta}$ is the penalty factor. $\mathbf{c}_{\mathbf{1}}$ is the cost factor when the tractor is unloaded. $\mathbf{c}_{\mathbf{2}}$ is the cost factor of the tractor when it is loaded. $\boldsymbol{\chi}_{\mathbf{i j c}}$ is a $0-1$ variable. $\mathbf{y}_{\mathbf{k c}}$ is a $0-1$ variable. $(\mathbf{k}=\mathbf{1}, \mathbf{2}, \ldots, \mathbf{K} ; \mathbf{i}=\mathbf{0}, \mathbf{1}, \ldots \mathbf{n} ; \mathbf{j}=$ $\mathbf{0}, \mathbf{1}, \ldots, \mathbf{n} ; \mathbf{c}=\mathbf{1}, \mathbf{2}, \ldots, \mathbf{C}) . \mathbf{T}(\mathbf{C})$ is the $\mathbf{C}$ car to complete all tasks in total time. The total time varies with the number of vehicles used $\mathbf{C}$, we set the total number of tasks completed less than $\mathbf{T}$.

Build model. The following models are established.

Objective function:

$\min \{\mathrm{N}\}$

$\min \mathrm{F}=$

$c_{1}\left(\sum_{c=1}^{C} \sum_{i=0}^{n} \sum_{j=0}^{n} d_{i j} \chi_{i j k}-\sum_{i=0}^{n} \sum_{j=0}^{n} d_{i j} q_{i j} / L\right)+c_{2} \sum_{i=0}^{n} \sum_{j=0}^{n} d_{i j} q_{i j} /_{L}+\beta \sum_{a=1}^{A} \max \left(\mathrm{ET}_{\mathrm{a}}+\right.$ $\left.t_{\text {taf }}-\mathrm{B}_{\mathrm{ra}}, 0\right)$

Constraint condition:

$\mathrm{T}(\mathrm{C}) \leq \mathrm{T}$

$\mathrm{K}=\sum_{\mathrm{i}=0}^{\mathrm{n}} \sum_{\mathrm{j}=0}^{\mathrm{n}} \mathrm{q}_{\mathrm{ij}}(\mathrm{i}=0,1, \ldots, \mathrm{n} ; \mathrm{j}=0,1, \ldots, \mathrm{n})$

$\sum_{\mathrm{k}=1}^{\mathrm{C}} \mathrm{y}_{\mathrm{ac}}=1(\mathrm{c}=1,2, \ldots, \mathrm{C})$

$\mathrm{t}_{\mathrm{k}} \geq \frac{\mathrm{d}_{\mathrm{r}_{\mathrm{k}} \mathrm{s}_{\mathrm{k}}}}{\sum_{\mathrm{c} \in \mathrm{v}} \mathrm{v}_{2} \mathrm{y}_{\mathrm{kc}}}+2 \mathrm{t}_{\mathrm{z}}(\mathrm{k}=1,2, \ldots, \mathrm{K})$

$\sum_{\mathrm{i}=0}^{\mathrm{n}} \chi_{\mathrm{ioc}}=1(\mathrm{c}=1,2, \ldots \mathrm{C})$

$\sum_{\mathrm{i}=0}^{\mathrm{n}} \chi_{\mathrm{ilc}}-\sum_{\mathrm{j}=0}^{\mathrm{n}} \chi_{\mathrm{ljc}}=0(\mathrm{l}=1,2, \ldots, \mathrm{n} ; \mathrm{c}=1,2, \ldots, \mathrm{C})$

$\sum_{\mathrm{j}=0}^{\mathrm{n}} \chi_{0 \mathrm{jc}}=1(\mathrm{c}=1,2, \ldots, \mathrm{C})$

$$
t_{k e}-t_{k r}=t_{k}(k=1,2, \ldots, K)
$$

$\mathrm{t}_{\mathrm{kr}} \leq \mathrm{LT}_{\mathrm{k}}(\mathrm{k}=1,2, \ldots, \mathrm{K})$

$\mathrm{t}_{\mathrm{c}, \mathrm{k}+1, \mathrm{r}} \geq \mathrm{t}_{\mathrm{c}, \mathrm{k}, \mathrm{c}}\left(\mathrm{c}=1,2, \ldots, \mathrm{C} ; \mathrm{k}=1,2, \ldots, \sum_{\mathrm{k}=1}^{\mathrm{A}} \mathrm{y}_{\mathrm{kc}}-1\right)$

$\chi_{\mathrm{ijc}}= \begin{cases}0 & \mathrm{y}_{\mathrm{kc}}=\left\{\begin{array}{l}0 \\ 1\end{array}\right.\end{cases}$

Decision variable:

$\chi_{i j k}, y_{k c}$

$\min \{\mathrm{N}\}$ is the least number of vehicles used in the specified time. $\min F$ is the least transport cost.

\section{Algorithm Design and Example Analysis}

In this paper, Floyd and greedy algorithm are combined to solve.

Algorithm Steps. Solve the distance matrix $\left(D^{(k)}=\left(d_{i j}^{(k)}\right)_{n \times n}, k=0,1, \ldots n\right)$. Solve the path $\operatorname{matrix}\left(\mathrm{R}^{(\mathrm{k})}=\left(\mathrm{r}_{\mathrm{ij}}^{(\mathrm{k})}\right)_{\mathrm{n} \times \mathrm{n}}, \mathrm{k}=0,1, \ldots, \mathrm{n}\right)$. Find the shortest route. Use the greedy algorithm to select the route.

Example Simulation. A company has five loading and unloading operations (A,B,C,D,E) and one tractor dispatch field $(\mathrm{O})$ in a transportation task. All tractors start from the truck dispatching 
field, complete the task and return to the dispatch field. The distance between the loading and unloading points and the distance between the loading and unloading points to the dispatch point are shown in Table 1. The mean time to load and unload operation is shown in Table 2 . The relevant data are shown in Table 3. The loading and unloading path and the corresponding traffic volume are shown in Table 4.

Table 1 Distance from each operation point $[\mathrm{km}]$

\begin{tabular}{|c|c|c|c|c|c|c|}
\hline & O & A & B & C & D & E \\
\hline O & 0 & 38 & 115 & 130 & 125 & 87 \\
\hline A & 38 & 0 & 158 & 122 & 40 & 59 \\
\hline B & 115 & 158 & 0 & 127 & 199 & 160 \\
\hline C & 130 & 122 & 127 & 0 & 165 & 87 \\
\hline D & 125 & 40 & 199 & 165 & 0 & 107 \\
\hline E & 87 & 59 & 160 & 87 & 107 & 0 \\
\hline
\end{tabular}

Table 2 The mean time to load and unload operation [min]

\begin{tabular}{|c|c|c|c|c|c|}
\hline & A & B & C & D & E \\
\hline Time & 17 & 12 & 23 & 19 & 25 \\
\hline
\end{tabular}

Table 3 The relevant data

\begin{tabular}{|c|c|c|c|c|c|c|c|}
\hline $\mathrm{T}$ & $\mathrm{S}$ & $\mathrm{v}_{1}$ & $\mathrm{v}_{2}$ & $\mathrm{c}_{1}$ & $\mathrm{c}_{2}$ & $\mathrm{t}_{s}$ & $\beta$ \\
\hline $35 \mathrm{~h}$ & 7 & $80 \mathrm{~km} / \mathrm{h}$ & $60 \mathrm{~km} / \mathrm{h}$ & $\$ 2 / \mathrm{km}$ & $\$ 4.9 / \mathrm{km}$ & $5 \mathrm{~min}$ & 0.6 \\
\hline
\end{tabular}

Table 4 Path and operation amount

\begin{tabular}{|c|c|c|c|c|c|c|c|}
\hline Task & $\begin{array}{c}\text { Loading } \\
\text { point }\end{array}$ & $\begin{array}{c}\text { Unloading } \\
\text { point }\end{array}$ & $\begin{array}{c}\text { Traffic } \\
\text { volume }\end{array}$ & Task & $\begin{array}{c}\text { Loading } \\
\text { point }\end{array}$ & $\begin{array}{c}\text { Unloading } \\
\text { point }\end{array}$ & $\begin{array}{c}\text { Traffic } \\
\text { volume }\end{array}$ \\
\hline 1 & $\mathrm{~A}$ & $\mathrm{~B}$ & 1 & 9 & $\mathrm{C}$ & $\mathrm{D}$ & 1 \\
\hline 2 & $\mathrm{~A}$ & $\mathrm{~B}$ & 1 & 10 & $\mathrm{C}$ & $\mathrm{D}$ & 1 \\
\hline 3 & $\mathrm{~A}$ & $\mathrm{D}$ & 1 & 11 & $\mathrm{D}$ & $\mathrm{C}$ & 1 \\
\hline 4 & $\mathrm{~B}$ & $\mathrm{D}$ & 1 & 12 & $\mathrm{D}$ & $\mathrm{C}$ & 1 \\
\hline 5 & $\mathrm{~B}$ & $\mathrm{~A}$ & 1 & 13 & $\mathrm{E}$ & $\mathrm{B}$ & 1 \\
\hline 6 & $\mathrm{~B}$ & $\mathrm{C}$ & 1 & 14 & $\mathrm{E}$ & $\mathrm{B}$ & 1 \\
\hline 7 & $\mathrm{C}$ & $\mathrm{E}$ & 1 & 15 & $\mathrm{E}$ & $\mathrm{D}$ & 1 \\
\hline 8 & $\mathrm{C}$ & $\mathrm{E}$ & 1 & & & & \\
\hline
\end{tabular}

Result. The final distance matrix of the simulation is as follows.

$$
D^{(n)}=\left(\begin{array}{cccccc}
0 & 38 & 115 & 130 & 78 & 87 \\
38 & 0 & 153 & 122 & 40 & 59 \\
115 & 153 & 0 & 127 & 193 & 160 \\
130 & 122 & 127 & 0 & 162 & 87 \\
78 & 40 & 193 & 162 & 0 & 99 \\
87 & 59 & 160 & 87 & 99 & 0
\end{array}\right)
$$

The shortest route is as follows:

$\mathrm{O}-\mathrm{A}-(\mathrm{O})-\mathrm{B}-(\mathrm{O})-(\mathrm{A})-\mathrm{D}-(\mathrm{A})-\mathrm{C}-(\mathrm{A})-\mathrm{D}-(\mathrm{A})-\mathrm{C}-(\mathrm{A})-\mathrm{D}-\mathrm{A}-(\mathrm{O})-\mathrm{B}-(\mathrm{O})-$ $\mathrm{A}-\mathrm{D}-(\mathrm{A})-\mathrm{E}-\mathrm{B}-\mathrm{C}-\mathrm{E}-\mathrm{B}-\mathrm{C}-\mathrm{E}-(\mathrm{A})-\mathrm{D}-(\mathrm{A})-\mathrm{O}$

Transportation time is 39.108 hours. In the actual case, all tasks are required to be completed within 35 hours. In order to minimize the number of vehicles and transport costs, we use 3 tractors to complete the task at the same time. The transport route of the 3 tractors are as follows. 
The transport route of tractor 1 is $\mathrm{O}-\mathrm{A}-(\mathrm{O})-\mathrm{B}-(\mathrm{O})-(\mathrm{A})-\mathrm{D}-(\mathrm{A})-\mathrm{C}-(\mathrm{A})-\mathrm{D}-\mathrm{O}$. The transport route of tractor 2 is $\mathrm{O}-\mathrm{A}-(\mathrm{O})-\mathrm{B}-(\mathrm{O})-\mathrm{A}-\mathrm{D}-(\mathrm{A})-\mathrm{O}$. The transport route of tractor 3 is $\mathrm{O}-\mathrm{E}-\mathrm{B}-\mathrm{C}-\mathrm{E}-\mathrm{B}-\mathrm{C}-\mathrm{E}-(\mathrm{A})-\mathrm{D}-(\mathrm{A})-\mathrm{O}$. The data for the relevant results are shown in Table 5.

Table 5 The data for the relevant results

\begin{tabular}{|c|c|c|c|c|c|}
\hline $\begin{array}{c}\text { Tractor } \\
\text { number }\end{array}$ & $\begin{array}{c}\text { Unloaded } \\
\text { route }\end{array}$ & $\begin{array}{c}\text { Unloaded } \\
\text { distance[km] }\end{array}$ & $\begin{array}{c}\text { Load } \\
\text { distance[km] }\end{array}$ & $\begin{array}{c}\text { Transportation } \\
\text { time[h] }\end{array}$ & $\begin{array}{c}\text { Transportation } \\
\text { cost[\$] }\end{array}$ \\
\hline 1 & $\begin{array}{c}\text { O-A } \\
\text { D-O }\end{array}$ & 116 & 1602 & 28.15 & 7417.8 \\
\hline 2 & O-A & 116 & 346 & 7.22 & 1765.8 \\
\hline 3 & $\begin{array}{c}\text { D-(A)-O } \\
\text { B-C } \\
\text { D-(A)-O }\end{array}$ & 292 & 720 & 15.65 & 3765.6 \\
\hline
\end{tabular}

\section{Summary}

In this paper, the Floyd algorithm and the greedy algorithm are combined to establish the vehicle scheduling model, and its effectiveness is verified by an example. It is necessary to further study the design of the network and the reasonable layout of the station.

\section{References}

[1] L. Xue, J.X. Ma and W. Xu: Transportation Systems Engineering and Information Technology, Vol.5 (2011) No.5, p.200. (In Chinese)

[2] N.N.Xu: Research on the Optimization of the Tractor Trailer Transportation between Yan Tai to Da Lian (Ms., Maritime Affairs University of Dalian, China 2012), p.26. (In Chinese)

[3] Billy E. Gil let and Leland R. Miller: Operation Research, Vol. 22 (1974) No.3, p.340.

[4] Willard J: Vehicle Routing Using P-optimal Tabu Search (MS. Imperial College, Britain, 1989), p.110.

[5] S.W. Lin and C.C. Lu: Proceedings of the 9th Asia Pacific Industrial Engineering and Management Systems Conference, Vol. 1 (2008) No.3, p.135.

[6] P.Lei and D.X. Cheng: Transportation Enterprise Management, Vol.7 (2010) No.9, p.12.(In Chinese)

[7] H.Y.Dai: Study on the Operation Mode and Development Strategy of Shandong Automobile Transportation (MS., Jilin University, China 2009), p.34. (In Chinese)

[8] D.H.Sheng and M.C.Li: Transport in Jiangsu, Vol.23 (1994) No.1, p18. (In Chinese)

[9] Q.N.Wen: Research on the Operation Mode Design and Vehicle Scheduling Problem of the Dumping Transportation (Ph.D., Institutes of Technology of South China, China 2012), p.34. (In Chinese)

[10]Y.Wang: Study on Container Transportation Vehicle Scheduling Mode Separation (Ms., Wuhan University of Technology, China 2010), p.22. (In Chinese) 